\title{
A Disciplina Geologia Geral - Sistema Terra, Introdutória ao Curso de Geologia da USP: Conteúdo e Reflexões
}

\author{
Paulo César Boggiani' (boggiani@usp.br), Colombo Celso Gaeta Tassinari², Ciro Teixeira Correia ${ }^{2}$, \\ Horstpeter Herberto Gustavo José Ulbrich², Antonio Carlos Rocha Campos', Sonia Maria Barros de Oliveira', \\ Rogério Guitarrari Azzone ${ }^{3}$, Thiago Piacentini ${ }^{4}$ \\ 'Departamento de Geologia Sedimentar e Ambiental - Instituto de Geociências - USP \\ R. do Lago 562, CEP 05508-080, São Paulo, SP, BRA \\ ${ }^{2}$ Departamento de Mineralogia e Geotectônica - Instituto de Geociências - USP, São Paulo, SP, BRA \\ ${ }^{3}$ Programa de Pós-Graduação em Mineralogia e Petrologia - Instituto de Geociências - USP, São Paulo, SP, BRA \\ ${ }^{4}$ Programa de Pós-Graduação em Recursos Minerais e Hidrogeologia - Instituto de Geociências - USP, \\ São Paulo, SP, BRA
}

Recebido em 14 de fevereiro de 2007; aceito em 26 de março de 2007

Palavras-chave: curso de Geologia, disciplina introdutória, Geologia Geral, ensino de Geociências.

\section{RESUMO}

A disciplina Geologia Geral - Sistema Terra, foi concebida com o objetivo de proporcionar, a alunos do curso de Geologia, o entendimento amplo e integrado, embora introdutório, dos processos atuantes na geosfera terrestre e suas complexas interações. Por meio da familiarização com conceitos e técnicas geológicas básicas, a disciplina visa capacitar os estudantes a interpretar fenômenos geológicos, motivando-os a ampliar seus conhecimentos das Geociências. Tópicos mais gerais tratados incluem a visão da Terra como parte do Sistema Solar, as áreas de atuação profissional do geólogo e sua responsabilidade frente à sustentabilidade da Terra. A disciplina tem início, no primeiro semestre, com apresentação da evolução do pensamento geológico e, em seguida, com apresentações sobre a origem do Universo e do Sistema Solar. Prossegue com os conceitos básicos da dinâmica interna do planeta, com ênfase na Tectônica Global e nos processos formadores de rocha. Aulas práticas incluem o reconhecimento de minerais e rochas mais importantes, visualização de mapas topográficos e geológicos básicos e introdução ao uso de bússola Brunton. Discute-se, a seguir, a dinâmica externa, com aulas sobre intemperismo e origem, transporte e deposição dos sedimentos. Encerrase o semestre com aulas sobre ação geológica do gelo, rios, ventos e mares. Inicia-se o segundo semestre com a apresentação dos conceitos do tempo geológico, fundamentado com noções sobre Paleontologia, Estratigrafia e Geocronologia. As principais estruturas geológicas são apresentadas, destacando-se o uso da bússola Brunton para medição de atitudes de planos inclinados. A partir do exame de mapas geológicos, é enfatizada a importância de adquirir visões bi e tridimensionais dos terrenos representados, assim como das diferentes etapas da evolução geológica. A parte final da disciplina é dedicada à discussão da importância econômica dos recursos hídricos, energéticos e minerais, ainda acrescida de uma aula sobre a contribuição da Geologia nas obras de engenharia e ocupação urbana. Ao transcorrer da disciplina, as aulas são complementadas com palestras ministradas por profissionais das diferentes áreas de atuação profissional. Ao final, é apresentado um esboço sobre a geologia do Brasil e do Estado de São Paulo, com introdução sobre técnicas de mapeamento geológico. A primeira experiência de mapeamento é desenvolvida durante atividade de campo de dois dias, para a qual é exigido relatório. Também no final do segundo semestre, os alunos elaboram e apresentam seminários sobre temas tratados na disciplina. A equipe que ministra a disciplina vem buscando restringir ao mínimo o uso de nomenclatura técnica e aprimorar a concatenação entre os conceitos abordados entre uma aula e outra para, dessa forma, ser atingido o objetivo de apresentar o Planeta Terra de forma sistêmica.

Keywords: geological curriculum, introductory discipline, General Geology, Geosciences education, Earth System.

\section{ABSTRACT}

The discipline General Geology - The Earth System was introduced in the Geology course curriculum with the objective of providing first year students an ample and integrated view of physical, chemical and biological processes that affect Earth's geosphere, and of their complex interactions. Through a familiarization with basic theoretical and field geological concepts the 
discipline aims at allowing students to be able to interpret geological phenomena, thus stimulating them to enlarge their knowledge of the Geosciences throughout the rest of the curriculum. More general topics treated include a view of the Earth as part of the Solar system, of areas of professional activities of geologists and the important contribution they can make to Earth's environment sustainability. The discipline begins in the first semester with lectures on the evolution of the geological thought, origin of the Universe and the solar system. These are followed by talks on Earth's internal dynamics, in the context of global tectonics, and rock generation processes. Lab classes include recognition of most important mineral and rock types, and use of the Brunton compass. Topics of external dynamics follow, including weathering processes and origin, transport and deposition of sediments. At the end of the semester a series of lectures are given on glacial, eolian, fluvial and marine processes as external dynamic agents. The second semester initiates with lectures on geological time from the paleontological, stratigraphic and geochronological view points. Themain geological structures are then dealt with in connection with the use of the Brunton compass in their three-dimensional reconstruction. Examination of topographic and geological maps serves as a basis for understanding the geological evolution of an area. The final part of the program is devoted to lectures on Earth's geological resources, such as water, fossil fuels and minerals, as well as on the importance of Geology to Engineering. These are complemented by talks by invited, well-known, professional geologists from different specialties. During the two semesters, classroom and laboratory classes are intercalated with short (one day) field activities. A broad familiarization with the geology of State of São Paulo and Brazil completes the class-room activities of the discipline. A first experience with geological mapping is then offered, during a two-day field trip at the end of the semester, for which the presentation of reports is required. This is followed by presentation of seminars by the students on themes treated in classroom. As a general rule the teaching team of ST tries to restrict the use of specialized technical terms as a way to facilitate the transfer of knowledge from one topic to another by the students.

\section{INTRODUÇÃO}

A disciplina anual Geologia Geral - Sistema Terra foi criada em 1997, em reforma curricular do curso de Geologia do Instituto de Geociências da Universidade de São Paulo, em substituição às disciplinas Introdução à Geociências e Geologia Física, ambas semestrais e ministradas concomitantemente às, também semestrais, Elementos de Mineralogia e Mineralogia Geral. A disciplina introdutória ao curso de Geologia passou a ser anual e foi organizada no sentido de ser ministrada de forma sistêmica, no contexto do conceito do Sistema Terra. Naquela época, tinha-se em mente, ainda, a intenção de, através dessa nova disciplina, diminuir as taxas de evasão relativamente altas do curso, já entre os alunos ingressantes.

Na estrutura curricular prévia, o conteúdo da Geologia Geral estava dividido em três disciplinas, a chamada Introdução à Geociências (disciplina do primeiro semestre, com 60 horas-aulas), onde o aluno recebia aulas introdutórias sobre os materiais terrestres, aos processos geológicos e à Tectônica Global, seguida no segundo semestre por Geologia Física (60 horas-aulas), com ênfase na avaliação de mapas e no treinamento em modelagens tridimensionais e a compreensão da história geológica, ainda complementadas por outra disciplina de Introdução à Mineralogia e à Petrologia, ministrada no primeiro semestre (60 horas-aulas) que se concentrava na familiarização e discussão sobre os minerais e rochas mais comuns, e seus respectivos processos formadores. $\mathrm{O}$ aluno cursava, ainda no primeiro ano, no segundo semestre, a Disciplina Mineralogia Geral (60 horas-aulas). Nessa estrutura, o campo de conhecimentos da Geologia encontrava-se dividido em compartimentos quase estanques, o que dificultava o entendimento e cone- xão, por parte do aluno, dos conteúdos das disciplinas, já que os docentes da Introdução à Geociências não estavam, necessariamente, em sintonia com os que ministravam a Geologia Física no semestre seguinte. As divergências eram também significativas com a temática da Introdução à Mineralogia, disciplina ministrada por docentes de outro departamento, cujo programa mostrava superposições com o que era oferecido na Introdução à Geociências. A unificação das temáticas introdutórias numa só disciplina deve ser considerada um avanço na nova proposta curricular.

Desde a estruturação da nova disciplina introdutória, na forma de Sistema Terra, ministrada pela primeira vez em 1998, modificações foram sendo implementadas até adquirir o formato que vem sendo aplicado nos últimos três anos, o qual é apresentado e discutido no presente texto.

A disciplina, de caráter anual, é ministrada, em seqüência, no primeiro e segundo semestre. Apresenta carga-horária total de 180 horas-aulas, divididas entre aulas teóricas e práticas, complementadas com 8 dias de aulas de campo, acrescida de seminários apresentados pelos alunos.

Discussões recentes sobre a disciplina ficaram em torno de qual deveria ser o foco principal, se voltado a apresentar ao aluno ingressante o panorama da carreira que optou, para sua vida profissional, ou às bases da Geologia como ciência, tendo sido optado por uma abordagem mista, tendo como base a estrutura usualmente adotada nos demais cursos de Geologia. Para o objetivo de apresentar as áreas de atuação do geólogo, além das informações fornecidas ao longo das aulas da disciplina introdutória, considerou-se importante dar continuidade e ampliar o número de palestras com profissionais das geociências que atuam em áreas e instituições diversas, o que se mostrou produtivo e de grande interesse por parte dos alunos ingressantes. 
Ao final do texto, é apresentada avaliação geral da disciplina e sugestões, principalmente com relação à integração com demais disciplinas do curso, face à importância, de uma disciplina introdutória, para o prosseguimento do aluno ao longo do curso de Geologia.

\section{OBJETIVOS DA DISCIPLINA}

A disciplina em questão difere das disciplinas, de caráter de Geologia Geral, ministradas aos demais cursos da USP, como o de Geografia, Biologia, Oceanografia, Geofísica, assim como outras, mais sintetizadas, ministradas aos curso de engenharia da Escola Politécnica da USP. Nesses cursos, a disciplina de Geologia Geral, com carga horária de um terço da destinada à Disciplina Geologia Geral - Sistema Terra, por vezes, é o único contato que o aluno terá, durante sua formação, com as geociências, não podendo ser caracterizada como introdutória e sim “terminalizante”, como apontado em Amaral (1981), uma vez que será a única disciplina na qual o aluno terá contato com as Geociências. Já para os alunos de um curso de Geologia, entretanto, a disciplina apresenta, de fato, caráter introdutório e assim é que deve ser encarada sua estruturação e definição de abordagem, conteúdos e objetivos.

Através de discussões periódicas mantidas entre os docentes e monitores, envolvidos com a disciplina introdutória do curso de Geologia, ao longo de 2005 e 2006, procurou-se delinear os seguintes objetivos para a disciplina, na busca de manter o caráter original de apresentar o Planeta Terra de forma sistêmica:

1. introdução aos conceitos da Geologia;

2. apresentar a nomenclatura básica sobre os materiais terrestres (minerais, rochas e estruturas geológicas), a fim de que o aluno passe a ter compreensão mínima para poder observar e discutir sobre os processos geológicos atuantes em seu interior (dinâmica interna) e na superfície (dinâmica externa), assim como a interação entre ambos;

3. contextualização dos processos geológicos no tempo geológico e relação com o ambiente atual, no âmbito do meio físico, biótico e sócio-econômico e cultural;

4. conhecimento das áreas de atuação do geólogo;

5. fornecer conhecimento prévio sobre as futuras disciplinas do curso e, finalmente, proporcionar ao aluno profunda reflexão sobre sua vocação para atuar em Geologia.

Outra questão central, buscada numa disciplina introdutória, é a de desenvolver, no aluno, o raciocínio geológico, ou seja, possibilitar que ele passe a entender como o Planeta Terra funciona, ou seja, qual o papel da dinâmica interna e externa e de como essas se relacionam através da Tectônica Global. Para esse objetivo, busca-se também o desenvolvi- mento da habilidade de pensar em três dimensões, a partir de visualizações bidimensionais, através de mapas.

Complementar ao desenvolvimento do raciocínio geológico, procura-se passar ao aluno a necessidade de se trabalhar em escalas diversas, tanto dimensionais quanto temporais. Procura-se mostrar como processos relativamente lentos são significativos em termos de processo geológico, como por exemplo, a erosão em escala continental e acumulações de sedimentos em bacias sedimentares, ao mesmo tempo em que o aluno é levado, de forma abstrata, a raciocinar desde dimensões nanométricas, ao âmbito de átomos em minerais, até, de forma integrada, a dimensões quilométricas quando, por exemplo, estuda os processo atuantes numa câmara magmática. De forma semelhante, são apresentados processos contrastantes na escala do tempo, relacionados a variações de modelos e paradigmas, como os relacionados aos princípios do Atualismo e Uniformitarismo, como a acumulação sedimentar resultante de processos lentos, como os que ocorrem nos fundos marinhos, contrapostos a sedimentações catastróficas de uma tempestade em uma praia, ou de avalanches no sopé de montanhas.

Paralelo ao desenvolvimento do raciocínio geológico, é procurado também passar ao aluno questões práticas consideradas importantes para seu prosseguimento no curso, inclusive como proceder nas aulas de campo. Neste sentido, são abordadas considerações ligadas à segurança do trabalho e aos métodos de trabalho envolvidos nestas aulas específicas. Cite-se, por exemplo, a preocupação em se transmitir critérios significativos de como registrar as observações geológicas em caderneta de campo, quer por meio de textos, desenhos e esquemas claros e objetivos, e até critérios para identificação do local visitado e do material coletado.

Por ser através da disciplina introdutória que a maioria dos alunos tem contato com o curso universitário, procurase proporcionar, também, introdução às práticas básicas de metodologia de ciências, incentivando-o a realizar pesquisa bibliográfica na biblioteca, aprender a sistematizar e ordenar informações e de como apresentá-las em relatório, o que é feito através de seminários e elaboração de relatório de mapeamento geológico simplificado, realizado ao final da disciplina.

Além dos objetivos citados, procura-se despertar o interesse do aluno pelas ciências geológicas e motivá-lo a se aprofundar no conhecimento das mesmas, ainda mais em função de, no primeiro ano, o aluno do curso de Geologia voltar sua atenção e dedicação mais às disciplinas não geológicas, como as de Matemática, Física, Química e Biologia, o que decorre da dificuldade em acompanhá-las, o que tem sido apontado como resultado da deficiência do Ensino Básico, na preparação do aluno para o ensino universitário. 


\section{ORIENTAÇÃO AOS ALUNOS}

Os alunos que ingressam nos cursos universitários, a cada ano que passa, têm encontrado dificuldade crescente para se adaptar à nova forma de aprendizado, o que vem a ser uma verdadeira ruptura no esquema ao qual estavam acostumados no Ensino Médio, cada vez mais próximos aos dos cursinhos preparatório para o vestibular, caracterizados por ensino simplificado e voltado ao restrito objetivo de aprovação nos exames vestibulares. O uso excessivo de apostilas e textos orientados, tendo como exemplo o fato de que o aluno não mais lê os livros clássicos da literatura mas apenas sinopses, tem feito com que o aluno tenha muita dificuldade em buscar a informação, ficando sem saber por onde estudar determinado assunto.

No sentido de procurar dar uma orientação mais pessoal aos alunos ingressantes, foi estruturado o Programa de Orientação ao Aluno do Primeiro Ano - POPA, pela Profa. Maria Cristina Motta de Toledo, o qual consiste na distribuição de 4 a 5 alunos para cada professor do Instituto que atua na forma de tutor, ao longo de seu primeiro ano do curso. Nos primeiros anos do programa o resultado foi bom, até o ponto de muitos dos alunos prosseguirem com atividades com os professores tutores, na forma de projetos de iniciação científica. Porém, nos anos seguintes, notou-se certa desmotivação por parte dos alunos e dos docentes, de tal forma que, no ano de 2006, o programa não teve seguimento, mas com recomendação de sua retomada, no ano de 2007. Provavelmente um dos motivos da desmotivação, ao menos por parte dos alunos, tenha sido a falta de orientação clara e objetiva de como os tutores deveriam proceder, do que resultou em atitudes heterogêneas, por parte dos tutores e dos alunos.

Como sugestão, para a retomada do programa de tutoria, poderiam ser elaboradas periodicamente orientações conjuntas de tarefas e atividades para os tutores, repassadas a eles pelo coordenador do programa da disciplina, de tal forma que todos os alunos receberiam atendimento mais homogêneo. Outra sugestão seria a de que as atividades de tutoria estivessem mais vinculadas à disciplina introdutória. Como exemplo, os tutores poderiam receber a programação da disciplina e, assim, acompanhar os alunos quanto aos conceitos aplicados e, dessa forma, obter um retorno de como estariam sendo o aproveitamento por parte dos alunos, além de envolvimento, de forma indireta, dos demais docentes do curso com a disciplina introdutória.

Os alunos do primeiro ano reclamam de não saber por onde estudar. Essa reclamação resulta do fato de a disciplina não seguir um livro texto, apesar de ter como base principal o livro "Decifrando a Terra” de Teixeira et al. (2000), organizado segundo o conceito de Sistema Terra. Constatase, contudo, que os alunos vêm do Ensino Médio com a cultura da apostila e têm dificuldade de buscar informações, apesar dos recursos modernos da Era Digital e da Internet. Para suprir essa deficiência, os alunos têm sido estimulados a pesquisar na biblioteca, para o que é oferecida orientação, pela equipe da Biblioteca do IGc-USP, de como encontrar livros, periódicos e mapas, mas o que se tem notado é que o hábito de freqüentá-la é ainda restrito, devendo ser encontradas formas de estimular, ainda mais, seu uso, inclusive da mapoteca e videoteca, talvez na forma de atividades práticas ou mesmo tarefas exigidas fora da sala de aula.

Outra forma sugerida, mas ainda pouco utilizada, é a de colocar questões ao final de cada aula com referências bibliográficas a respeito do tema ministrado, para se evitar que o aluno venha a estudar apenas às vésperas das provas as quais necessitam de aprimoramento, uma vez que são ainda embasadas em provas escritas, apesar de relativo aumento de questões práticas, como identificação e descrição de rochas e uso de bússola Brunton. Há necessidade de se calibrar adequadamente o peso de cada questão colocada nas provas, no sentido de se evitar dar o mesmo peso para tópicos claramente de importância desigual e falta, ainda, o estabelecimento de um exame final integrador, através do qual os objetivos propostos da disciplina pudessem, de fato, serem avaliados se foram ou não cumpridos, sendo que a avaliação do aluno é ainda realizada de forma compartimentada.

\section{CONTEÚDO DA DISCIPLINA}

A Disciplina inicia-se com a apresentação da programação (Quadro 1) e de seus objetivos, quando também são apresentados, aos futuros geólogos, suas áreas de atuação, em complementação às atividades da semana de recepção aos alunos ingressantes, quando já é procurado fornecer ao aluno contato com as áreas de atuação do geólogo.

Quadro 1. Programa da 0440100 - Disciplina Geologia Geral - Sistema Terra. Disciplina introdutória ao curso de Geologia do Instituto de Geociências USP (ano de referência 2006).

\section{$1{ }^{\circ}$ Semestre/2006}

- Apresentação do programa e dos objetivos da disciplina e datas das provas e das aulas de campo

- Evolução do Pensamento Geológico seguido de visita ao Museu de Geociências do IGc

- Universo, Sistema Solar, Planeta Terra e Meteoritos, seguida de visita orientada à biblioteca

- Introdução aos Minerais (aula teórica e prática)

- Estrutura Interna da Terra

- Aula prática sobe minerais

- Distribuição do fluxo térmico na Terra 
- Introdução aos principais tipos de rochas

- Processos formadores de rocha

- Reconhecimento dos três tipos de processos formadores de rocha

- Introdução à Tectônica Global

- Exercícios com mapas topográficos e uso de bússola Brunton

- Avaliação sobre dinâmica interna e processos formadores de rochas

- Aula prática sobre rochas ígneas

- Tectônica Global e rochas ígneas (vulcanismo)

- Aula prática sobre rochas sedimentares

- Tectônica Global e bacias sedimentares

- Aula prática sobre rochas metamórficas

- Tectônica Global e rochas metamórficas

- Avaliação sobre rochas (teoria e prática) e Tectônica Global

- Aula de Campo em Perus (SP) - rochas ígneas e minerais

- Aula sobre caderneta de campo

- Intemperismo e formação dos solos

- Intemperismo

- Mudanças climáticas, hidrosfera e atmosfera

- Aula de campo - Pirapora do Bom Jesus e Araçariguama (roteiro anexo)

- Ação geológica do gelo e rios

- Aula prática com mapas e perfis geológicos (rochas ígneas e sedimentares)

- Aula de Campo na Serra do Mar e Baixada Santista (roteiro anexo)

- Ação geológica dos ventos e mares

- Aula prática com sedimentos (texturas)

- Avaliação sobre dinâmica Externa

$2^{\circ}$ Semestre/2006

- História geológica da vida (Paleontologia)

- Estratigrafia, datação relativa e correlações

- Aula de campo - Itaquaquecetuba (SP), sedimentos fluviais

- Tempo Geológico

- Aula prática - medição de atitude de planos com bússola Brunton

- Dobras e falhas

- Exercícios com dobras e falhas e mapas

- Revisão sobre os processos formadores de rochas metamórficas

- Aula de campo - medição de planos em dobra

- Revisão sobre Tempo Geológico

- Avaliação Evolução/Estratigrafia/Deformação/metam/Tempo Geológico

- Água Subterrânea (hidrogeologia)

- Exercício com mapa sobre hidrogeologia

- Geologia de Engenharia e aplicada ao meio ambiente

- Exercício com o Atlas Ambiental de São Paulo

- Recursos Minerais

- Exercício sobre avaliação de jazida mineral
- Recursos Energéticos

- Apresentação dos Seminários

- Geologia do Brasil

- Apresentação dos Seminários

- Geologia do Estado de São Paulo

- Aula de campo preparatória ao mapeamento (roteiro anexo)

- Preparação para o mapeamento geológico

- Aula de campo (dois dias) com introdução à atividade de mapeamentos geológicos

- Orientação para elaboração de relatório

- Avaliação sobre aplicação das Geociências na Sociedade

- Avaliação substitutiva

- Avaliação de recuperação (para aluno que não obteve média para aprovação)

Total de 180 horas-aulas:

92 horas-aulas teóricas;

40 horas-aulas práticas;

48 horas-aulas de campo (6 aulas de um dia e 1 aula de dois dias, cada dia de campo $=6$ horas-aulas).

Cinco avaliações, com uma avaliação substitutiva e uma avaliação de recuperação (para o aluno que não obteve média).

$\mathrm{Na}$ avaliação, são também contabilizadas notas de caderneta de campo, relatório do mapeamento e seminário.

A Disciplina é de 180 horas-aulas, ministradas às terçasfeiras, das $8 \mathrm{~h}$ às $12 \mathrm{~h}$, e às quintas-feiras, das $14 \mathrm{~h}$ às $16 \mathrm{~h}$. As aulas de quinta-feira são teóricas, com assuntos que podem, sempre que possível, serem retomados nas aulas de terçafeira, geralmente de cunho prático ou de campo. O final da tarde de quinta-feira, das $16 \mathrm{~h}$ às $18 \mathrm{~h}$, tem sido utilizado para palestras complementares, o que já se iniciou, mas de forma ainda incipiente, sobre tópicos específicos do conteúdo da disciplina ou sobre aspectos mais gerais, relacionados ao exercício da profissão, quando ministras por profissionais com atuação destacadas no tema desenvolvido na palestra.

As aulas de campo, no total de 8 dias, são realizadas às terças-feiras, com seis aulas de um dia e uma aula de dois dias, ao final da disciplina, como atividade de introdução ao mapeamento geológico. As aulas de campo são relacionadas às aulas teóricas ministradas anteriormente e têm o objetivo de apresentar, no campo, conceitos e feições geológicas apresentadas em aula a fim de reforçar identificação e entendimento.

Dado ao dinamismo das ciências, ao qual a Geologia não é exceção, existe a necessidade da reformulação constante da programação, até porque as equipes de docentes responsáveis têm sido também periodicamente modificadas, assim os atuais desafios de busca de soluções para os problemas decorrentes do efeito estufa, colocam esse tema 
como um dos que merecem aprofundamento, além do que já vem sendo apresentado quando se trata das mudanças climáticas, no âmbito do conteúdo da dinâmica externa. Neste aspecto, deverão ser inseridos temas relativos ao Mecanismo de Desenvolvimento Limpo (MDL) e os relativos a vulnerabilidades decorrentes das mudanças climáticas, com exemplos de MDL's relacionados à Geologia, como o uso de pozolana na indústria de cimento, estocagem de gás em campos abandonados de petróleo, além de outros, como os sugeridos por Marcovitch (2006, pg. 107-108).

Foi introduzida, recentemente, uma aula sobre a evolução do pensamento geológico, na qual são apresentadas os fundamentos teóricos principais das ciências geológicas, como por exemplo as várias concepções de tempo geológico, como a idéia de tempo infinito de James Hutton, com ênfase no conceito de discordância por ele introduzido, e as formas diversas pelas quais se interpretou a origem das rochas, como o conceito de neptunismo, introduzido por Werner. Procura-se, ao apresentar a evolução das diferentes concepções científicas, mostrar o contexto histórico na qual foram geradas como, por exemplo, a disputa entre criacionistas e evolucionista, para determinação da idade da Terra, até a descoberta da radioatividade e sua aplicação na datação radiométrica de minerais e rochas. Neste mesmo contexto, são apresentados os princípios e evidências que levaram à formulação do conceito da Tectônica Global, tendo como predecessor Alfred Wegener, com sua teoria da Deriva dos Continentes, e sua importância na formulação das bases da Geologia Moderna.

Segue-se com o esquema usual do campo da Geologia Geral, iniciando-se com as hipóteses modernas sobre a origem do Universo e como, a partir desse, originou-se o Sistema Solar e o Planeta Terra, com aula especialmente ministrada pelo Prof. Roberto Boczko do Instituto de Astronomia, Geofísica e Ciências Atmosféricas (IAG-USP). As demais aulas são referente a conceitos básicos da dinâmica interna do planeta, com ênfase na Tectônica Global com explicações de como se interpreta ser o interior da Terra e de que forma são feitas essas deduções.

Em paralelo, à aplicação dos conceitos teóricos da Dinâmica Interna, são realizadas aulas práticas, quando são introduzidos os conceitos básicos sobre minerais e rochas e sobre mapas topográficos e uso de bússola Brunton.

A parte seguinte da disciplina passou, recentemente, a ser concentrada nos processos formadores de minerais e rochas, com estímulo aos alunos para o reconhecimento e entendimento da origem de cerca de 30 rochas mais comuns, tendo como recurso, além do trabalho com amostras, o uso de exercícios com mapas, onde ênfase é dada para desenvolvimento da habilidade de observação e descrição das amostras, com diferenciação de aspectos texturais e estruturais.
A primeira aula de campo tem sido ministrada em exposição de granito e metassedimentos do Grupo São Roque, na região de Perus, nas proximidades da cidade de São Paulo, em afloramento no quilômetro 0,5 do Rodoanel Mário Covas, sendo essa o primeiro contato com o trabalho de campo, na forma de aula, já que atividades de campo vêm sendo realizadas durante a semana de recepção, nos primeiros dias de aulas. Os alunos são orientados para, em primeiro lugar, observar os tipos de rochas e estruturas presentes, para somente depois passarem a fazer descrição mais detalhadas dos litotipos encontrados (minerais, granulação, cor, estrutura e textura), acompanhada de desenhos e esquemas ilustrativos, dando importância ao uso de diferentes escalas.

Até o final do semestre, as aulas passam a ser referentes à dinâmica externa, com aulas sobre mudanças climáticas, intemperismo e origem dos sedimentos, as quais são complementadas com duas aulas de campo, uma para a região de Pirapora do Bom Jesus e Araçariguama (SP), onde os alunos têm a oportunidade de observar e entender como atua o intemperismo sobre diferentes tipos de rocha, e outra para a Serra do Mar e Baixada Santista, para entendimento da "biografia de um grão de areia” (Giannini, 2000), ou seja, os caminhos e processos a que estão sujeitos os clastos encontrados em sedimentos de rios e praias, desde a áreafonte. A atividade de campo na Serra do Mar, com observação de diferentes contextos de sedimentação, ou seja, o Rio Cubatão em seu curso médio, área de mangue e de praia, têm mostrado grande interesse por parte dos alunos por possibilitar bom entendimento do funcionamento da dinâmica externa. São coletados sedimentos, nos diferentes ambientes observados, inclusive com obtenção de fração de minerais pesados, através do uso de bateia e imãs, para posterior análise das características mineralógicas e texturais em sala de aula. São também destacados os processos de movimentação de massa em áreas de risco geológico da Serra do Mar, com discussão sobre as dificuldades encontradas para as várias formas de transposição da encosta da Serra do Mar, desde as primeiras trilhas indígenas, aproveitadas e aperfeiçoadas pelos primeiros exploradores europeus, passando por antigas ferrovias, até os modernos dutos e rodovias expressas. Nessa aula, há ainda a possibilidade de iniciar o aluno no treinamento de localização do ponto de observação com mapa topográfico e uso de aparelho de posicionamento por satélites (GPS).

Na aula de campo sobre intemperismo, em Pirapora do Bom Jesus e Araçariguama (SP) são feitas observações de afloramentos ao longo da Rodovia dos Romeiros, antiga rota de tropeiros para o interior de São Paulo, às margens do Rio Tietê, para investigação da variação características dos diferentes tipos de rochas encontrados. A iniciativa à observação é estimulada, assim como interpretações formuladas pelos próprios alunos, como a proporcionada pelo estudo de aflora- 
mento de lavas almofadadas em Pirapora do Bom Jesus, onde os alunos reconhecem essa estrutura, com base em observações próprias e no que foi apresentado em sala de aula.

Tem-se procurado ampliar o procedimento de motivar o aluno à observação e formulação de suas próprias interpretações, principalmente em aulas de campo, em substituição de extensas explicações prévias sobre a geologia de um determinado afloramento. A indução é realizada através de roteiros, onde, para cada parada, são listadas as atividades a serem realizadas e os principais aspectos a serem observados, conforme os três exemplos anexos: um sobre a aula de campo sobre intemperismo, na região de Pirapora do Bom Jesus e Araçariguama, o segundo para a aula de campo da Serra do Mar e o terceiro para aula na região de Itu, preparatória para as aulas de mapeamento de fim de curso, todas no Estado de São Paulo.

No atual estágio da disciplina, nota-se que os alunos passam a demonstrar preocupação com a dificuldade encontrada para preenchimento da caderneta de campo, apesar da orientação prévia fornecida. As cadernetas de campo são recolhidas imediatamente ao final da atividade de campo e, ao se depararem com as correções realizadas pelos monitores, passam a questionar o que seria mais significativo descrever e representar, a partir das observações de campo. Ao se identificar esse momento de análise crítica de sua forma de proceder no campo, procura-se dar a devida orientação a respeito dos aspectos fundamentais que devem ser observados, anotados e esquematizados com base em discussão sobre imagens projetadas de afloramentos já estudados.

O final do primeiro semestre é fechado por aulas teóricas sobre a ação geológica do gelo, rios, ventos e mares, como agentes da dinâmica externa do planeta, os quais, dada à possibilidade de observação direta dos processos e produtos, inclusive nas aulas de campo, permitem serem abordados com detalhes e com o objetivo de desenvolver o senso de observação e interpretação do aluno.

O início do semestre seguinte se dá com a apresentação dos conceitos do Tempo Geológico, para o que são ministradas aulas introdutórias sobre Paleontologia, Estratigrafia e Geocronologia, quando os conceitos de idade relativa e absoluta são discutidos extensivamente, no contexto do uso geológico dos fósseis. Atenção especial tem sido dada ao uso de Bússola Brunton, a qual tem se demonstrado mais eficiente para entendimento das relações entre direção e mergulho de planos do que as bússolas do sistema Clar. O uso correto desse instrumento é avaliado em aula de campo específica e através de prova prática, além do estímulo para treinamento fora da sala de aula, com uso de modelos em madeira.

O entendimento de modelos tridimensionais a partir de configurações bidimensionais, através de mapas geológicos esquemáticos, é também exigido, assim como entendimento da evolução geológica e ênfase nas estruturas geo- lógicas (dobras e falhas). Pretende-se, com esses exercícios, que o aluno passe a montar modelos tridimensionais em sua mente, acompanhado do entendimento da evolução geológica, no sentido de ressaltar o caráter histórico da ciência geológica, ou seja, a sua preocupação com o tempo e o desenvolvimento e evolução dos processos que atuam no planeta, o que diferencia a Geologia das demais ciências naturais (Silva et al., 1981).

A parte final da disciplina é dedicada à apresentação da aplicação da Geologia aos recursos hídrico, energéticos e minerais, passando pela Geologia de Engenharia. Nesse momento, tem-se procurado complementar as aulas com palestras ministradas por profissionais de áreas distintas, a fim de que o aluno tenha uma melhor visão da atuação do geólogo, atividade essa ainda incipiente e que se pretende ampliar nos anos subseqüentes.

Aula prática específica é realizada com base na análise do Atlas Ambiental de São Paulo (Sepe e Takiya, 2004), com a colocação de problemas ambientais de forte impacto, como, por exemplo, a localização de um novo aterro sanitário para a cidade de São Paulo, face ao fato dos dois, em atividade, virem a ter suas capacidades esgotadas em um ano, com ênfase para terem atenção às condições geológicas necessárias para esse tipo de obra e sua localização frente aos mananciais de água da cidade. Outro exemplo útil a vir a ser empregado seria o acidente nas obras de escavação da Linha Amarela do Metro da Cidade de São Paulo, o que possibilita, ainda, tratar de temas geológicos relacionados a obras de engenharia e explicar, de forma mais aprofundada, como se deu o processo de ocupação da cidade sobre antigas áreas de várzeas, após a retificação dos rios Tietê e Pinheiros, para projeto de produção de energia elétrica, formando o que Ab’ Sáber (1980) chama de “terraços antrópicos”. Esses assuntos permitem ainda aprofundar conceitos já utilizados sobre geomorfologia e sedimentação fluvial, os quais são também posteriormente trabalhados em aula de campo em lavra de areia em Itaquaquecetuba (SP).

O fecho da disciplina é dado com a apresentação de noções sobre Geologia do Brasil e do Estado de São Paulo, em parte como preparação teórica para a etapa de dois dias de mapeamento final, para a qual também é ministrada aula de campo específica de um dia na região de Itu (SP), na borda leste da Bacia Sedimentar do Paraná, mostrando as feições características de litologias ígnea, metamórfica e sedimentar que os alunos irão encontrar no campo. Também como preparação para esta atividade final de campo, são discutidas com maior detalhe as técnicas de mapeamento geológico.

Ainda, ao final da disciplina, é exigido ao aluno a organização e apresentação de seminário, o que tem se demonstrado ser uma boa forma de avaliar seu progresso e amadurecimento ao longo do primeiro ano do curso. Para essa 
atividade, os alunos são organizados em grupos de três e o tema é escolhido a partir de uma lista montada entre os docentes. Na primeira vez que foi exigida, a escolha por parte dos alunos foi livre, dentro de um conjunto amplo de temas geológicos, muitos nem ao menos mencionados nas aulas anteriores. Na segunda vez dessa experiência, em 2006, face ao fato de ter sido observado que os alunos ainda não haviam assimilado os conteúdos principais da disciplina, optou-se para que escolhessem temas referentes à própria disciplina, como forma de reforçar o aprendizado sobre os mesmos. A experiência foi considerada boa, motivo pelo qual é sugerido que seja dada continuidade à manutenção de temas relacionados aos da disciplina.

A organização dos seminários é feita no segundo semestre, quando os alunos já se encontram com a base necessária para seu desenvolvimento. Após distribuição dos alunos, em grupos, e escolha do tema, estes procuram os docentes da área relacionada e são orientados a como fazer pesquisa bibliográfica, com a exigência de organizarem lista dos principais trabalhos para montagem do seminário. Em seguida é exigido um texto curto, de duas páginas, após discussão, com o docente responsável pela orientação, quanto aos tópicos principais que serão apresentados, além da orientação quanto a como proceder na apresentação e montagem dos diapositivos, a serem exibidos em data show. As apresentações dos seminários são realizadas em conjuntos, com temas relacionados, com duração de 20 minutos, para as quais o aluno que irá apresentar é sorteado, no início da mesma, entre os membros de cada grupo.

\section{AVALIAÇÃO SOBRE A DISCIPLINA}

A avaliação final é que a disciplina deve ainda ser aprimorada quanto à concatenação lógica dos diferentes tópicos e no sentido de evitar repetições ou sobreposições com outras disciplinas. Tem sido buscada, entre os docentes envolvidos, a utilização de nomenclatura e conceitos comuns assim como avançar no entendimento de quais seriam os tópicos que merecem maior destaque, mas há ainda a necessidade de ser estabelecido um fio condutor claro e consensual, que forneça, de fato, à disciplina o pretendido caráter sistêmico, onde o aluno visualize a relação dos temas abordados no conjunto da disciplina.

Para se atingir esta meta, uma das questões colocadas é a que a equipe de docentes deva ser suficientemente reduzida. Nos anos de 2005 e 2006, seis docentes foram destinados à disciplina, número esse que se considera não ideal, mas que já foi relativamente menor, se comparada ao passado, quando chegou a ser ministrada por equipe com até treze docentes. Entende-se que este excessivo número de docentes torna a disciplina fragmentada, com aprofundamento inapropriado sobre determinados temas, geralmente associados à especialidade do respectivo docente, com uso freqüente de termos muito específicos e desconhecidos pelo aluno, dificultando seu aprendizado.

O ideal seria que a disciplina fosse ministrada apenas por dois ou, no máximo, três docentes, com auxílio de monitores, face ao grande número de exercícios e cadernetas de campo cujas correções devem ser apresentadas e discutidas com os alunos, para que esses as verifiquem e superem suas dificuldades. A redução da equipe de docentes facilita a sua interação e conhecimento prévio dos conceitos já ministrados, antes do avanço dos demais, assim como a constante avaliação dos progressos obtidos e possíveis necessidades de modificações. A dificuldade encontrada, para viabilizar essa possibilidade, é que a disciplina é anual e com 180 horas-aulas a serem ministradas, sem contar as orientações aos trabalhos exigidos, fazendo com que os docentes responsáveis tenham que se dedicar, quase que integralmente, ao ensino da disciplina durante o ano inteiro.

Outra necessidade apontada é que deveria existir consenso sobre os tópicos mais importantes que se pretende ministrar. Na Geologia Geral, há uma tendência de se apresentar assuntos muito diversos e de forma superficial, quando o ideal seria, possivelmente, ministrar poucos conceitos, mas importantes, o que facilitaria também a avaliação do aluno. O equacionamento dessa questão é algo que se coloca como fundamental para o futuro da disciplina.

Os alunos demonstram dificuldade em acompanhar as aulas quando é empregada, por parte do docente, uma ampla gama de nomenclatura (minerais, rochas, estruturas etc.). Esta dificuldade foi, em parte, revertida, com a orientação aos docentes para empregarem, em suas explanações, apenas alguns nomes de minerais importantes e os trinta tipos principais de rochas das três classes e, assim, evitarem empregar outros que não fossem de conhecimento prévio do aluno. O aprofundamento em temas de Mineralogia e Petrologia acontece, na grade curricular atual, apenas a partir do segundo ano do curso, aspecto esse que merece reflexão, em futuras reformulações curriculares, sobre a possibilidade de vir a ser ministrado no primeiro ano.

Como indicado antes, o desenvolvimento do raciocínio geológico deve ser considerado um dos mais importantes objetivos da disciplina, objetivo este, entretanto, não devidamente alcançado. Este aspecto ainda não tem sido devidamente contemplado nas avaliações aplicadas aos alunos, o que merece ser, oportunamente, revisto.

A complementação das aulas, através de palestras, deve ser ampliada, inclusive com programa de palestras a serem ministradas pelos demais docentes do IGc, a fim de que esses passem a ter também mais contato com os alunos ingressantes, inclusive para facilitar o processo de iniciação científica, já no segundo ano do curso. 
Outra dificuldade encontrada, com a organização da disciplina introdutória, é a falta de um projeto pedagógico para o curso de Geologia como um todo, ressaltando-se que esse projeto é algo que deve vir a ser construído pelo conjunto de docentes envolvidos com o curso, a ser constantemente discutido e avaliado. Falta, no curso de Geologia da USP, uma discussão mais aprofundada sobre o tipo de geólogo que se quer formar, não apenas quanto ao aspecto do conteúdo mas, principalmente, no aspecto filosófico e ético. Diante dessa situação, é necessário admitir que os professores do Instituto têm apresentado uma atitude mais informativa, restrita à transmissão de conhecimento, e menos formativa, com desenvolvimento do senso crítico do aluno frente ao seu papel na sociedade, principalmente diante dos atuais desafios de carência de recursos naturais e das mudanças globais. Essa situação merece a devida atenção no sentido de ser melhor trabalhada no futuro.

A consideração acima foge ao alcance de uma única disciplina, como a analisada no presente texto, e deve ser pensada para o curso como um todo. No que tange porém, à disciplina introdutória, dado à sua importância, falta ainda maior interação com os docentes das demais disciplinas, cujos responsáveis devem comunicar as carências percebidas nos alunos, principalmente de conteúdo.

Espera-se que, com a recente reativação da Comissão Coordenadora do Curso de Geologia, a concatenação entre os conteúdos de todas as disciplinas do curso, e não apenas a introdutória, passe a ser trabalhada de forma mais ampla e freqüente. Esta questão deveria estar inserida no contexto de um projeto pedagógico, onde fique bem claro o perfil do geólogo que se pretende formar. Considera-se esse processo fundamental para se estruturar e ministrar uma disciplina com conteúdo e abordagem que seja consensual entre os demais docentes do curso, e não apenas dos docentes envolvidos com a disciplina introdutória.

\section{REFERÊNCIAS BIBLIOGRÁFICAS}

AB' SABER, A. N. Súmula geomorfológica do Planalto Paulistano. In: MESAREDONDAASPECTOS GEOLÓGICO E GEOTÉCNICOS DA BACIA SEDIMENTAR DE SÃO PAULO, 1980, São Paulo. Atas... São Paulo: ABGE/SBG Núcleo São Paulo, 1980. p. 33-36.

AMARAL, I. A. do. A geologia introdutória na universidade - análise de um modelo de curso. In: SIMPÓSIO NACIONAL DE GEOLOGIADO BRASIL, 1., 1981, Belo Horizonte. Teses. Belo Horizonte: Sociedade Brasileira de Geologia, 1981. p. 45-56. v. 1.

GIANNINI, P. C. F. Biografia de um grão de areia. In: TEIXEIRA, W.; TOLEDO, M. C. M.; FAIRCHILD, T. R.;
TAIOLI, F. Decifrando a terra. São Paulo: Oficina de textos, 2000.p. 170.

MARCOVICTH, J. Para mudar o futuro - mudanças climáticas, políticas públicas e estratégias empresariais. São Paulo: Saraiva/EDUSP, 2006. 366 p.

SEPE, P. M.; TAKIYA, H. Atlas ambiental do município de São Paulo - o verde, o território, o ser humano: diagnóstico e bases para a definição de políticas públicas para áreas verdes no Município de São Paulo. São Paulo: SVMA, 2004. 257 p.

SILVA, A.; VASCONCELOS, A. C. B. C. de; PASCHOALE, C. Uma base para a elaboração do currículo de geologia. In: SIMPÓSIO NACIONAL DE GEOLOGIA DO BRASIL, 1. , 1981, Belo Horizonte. Teses. Belo Horizonte: Sociedade Brasileira de Geologia, 1981. p 27- 43. v. 1.

TEIXEIRA, W.; TOLEDO, M. C. M.; FAIRCHILD, T. R.; TAIOLI, F. Decifrando a terra. São Paulo: Oficina de textos, 2000. 557 p. 


\title{
ANEXOS - ROTEIROS DE AULAS
}

\author{
Instituto de Geociências - USP \\ 2006 \\ 044100 - Geologia Geral - Sistema Terra (Bacharelado) \\ Aula de Campo II - Intemperismo - Pirapora do Bom Jesus e Araçariguama
}

Como procedimento geral, leia o roteiro abaixo e, para cada parada, observe atentamente os afloramentos. Reflita e discuta com os colegas. Ao final de cada parada, será realizada discussão geral quando serão apontados os principais aspectos abordados e fechamento do raciocínio.

Ao longo do trajeto da aula de campo, procure associar o tipo de relevo observado com o tipo de rocha predominante, verifique constantemente o mapa geológico.

Para cada parada, identifique, na caderneta de campo, a localização (estrada, quilometragem etc.).

Parada 1. Santana do Parnaíba, atrás da igreja matriz

- descreva e identifique o tipo de rocha (composição mineralógica, textura e estrutura);

- faça um esquema de como é o afloramento e da forma como as rochas estão expostas, faça um perfil esquemático do perfil de alteração e procure entender porque os corpos de rocha adquirem a forma de blocos arredondados.

Parada 2. Estrada dos Romeiros (Santana do ParnaíbaPirapora do Bom Jesus), km 43, entrada da Mineração POSOCAL

- descreva e identifique o tipo de rocha (composição mineralógica, textura e estrutura);

- faça esquemas das estruturas visíveis;

- faça medidas, com o clinômetro da bússola da inclinação das camadas (mínimo de cinco medidas);

- nas proximidades à uma empresa de mineração, qual tipo de minério é lavrado? Para qual finalidade?

- procure saber a que unidade estratigráfica pertencem essas rochas, verifique no mapa geológico.

Parada 3. Estrada dos Romeiros (Santana do ParnaíbaPirapora do Bom Jesus)

- descreva o perfil de alteração, sua espessura e forma como se apresenta o solo (cor, minerais presentes e textura);

- veja se é possível observar o tipo de rocha que originou o manto de alteração, procure interpretar.

Parada 4. Pirapora do Bom Jesus - a leste do Rio Tietê

- descreva e identifique o tipo de rocha (composição mineralógica, textura e estrutura);

- faça esquema da estrutura primária observada e interprete sua origem com base no que já foi visto e discutido em sala de aula;

- como é alteração intempérica da rocha, que tipo de material é produzido? Qual é a relação desse tipo de alteração com a exposição da parada anterior?

- observe a alta montanha ao Sul, que tipo de rocha você imagina ser constituída?

Parada 5. Estrada Pirapora do Bom Jesus - Araçariguama, base do Morro Voturuna

- descreva e identifique o tipo de rocha (composição mineralógica, textura e estrutura);

- descreva o tipo de material produzido pela alteração e como é o solo (espessura e minerais presentes);

- identifique a unidade estratigráfica (verifique no mapa geológico);

- procure saber a finalidade do material lavrado nas redondezas.

Parada 6. Estrada Pirapora do Bom Jesus - Araçariguama - faça um esquema do afloramento e das rochas aflorantes e relações entre os corpos de rocha observados;

- verifique os dois tipos de rochas presentes (use $\mathrm{HCl}$ ) e observe o comportamento frente ao intemperismo;

- reflita sobre a origem dessas rochas e discuta sobre os modelos genéticos propostos.

\section{Bibliografia complementar}

BERGMAN, M. Caracterização estratigráfica e estrutural da seqüência vulcano-sedimentar do Grupo São Roque na região de Pirapora do Bom Jesus, SP. 1988, 166 f. Dissertação (Mestrado) - Instituto de Geociências, Universidade de São Paulo, São Paulo, 1988.

FIGUEIREDO, M. C. H.; BERGMAN, M.; PENALVA, F.; TASSINARI, C. C. G. 1982. Ocorrência de pillow lavas no Grupo São Roque, SP. Ciência da Terra, v. 2, p. 6-8, 1982.

IPT - INSTITUTO DE PESQUISAS TECNOLÓGICAS. Mapa geológico do estado de São Paulo. São Paulo: IPT, 1981. Mapa. Escala: 1:500 000, com texto explicativo. 
JULIANI, C.; BELJAVSKIS, P. Revisão da litoestratigrafia da Faixa São Roque/Serra do Itaberaba (SP). Revista do Instituto Geológico, v. 16, n. 1/2, p. 33-58, 1995.

LAZZARI, M. L. O metabasito de Pirapora do Bom Jesus, SP. 1987, 96 f. Dissertação (Mestrado) - Instituto de
Geociências, Universidade de São Paulo, São Paulo, 1987.

TASSINARI, C. G.; MUNHÁ, J. M. U.; RIBEIRO, A.; CORREIA, C. T. 2001. Neoproterozoic oceans in the Ribeira Belt (southern Brazil): the Pirapora do Bom Jesus Ophiolitic complex. Episodes, v. 24, n. 9, p. 245-251, 2001.

\section{Instituto de Geociências - USP \\ 2006 \\ 044100 - Geologia Geral - Sistema Terra (Bacharelado) Aula de Campo III: Serra do Mar e Baixada Santista}

Atenção: reúnam-se em grupos de três para coleta das amostras.

\section{CADERNETAS INDIVIDUAIS E MAPAS INDIVIDUAIS!}

Objetivos:

- investigar processos de origem de sedimentos;

- estudar relação entre sedimentos e nível de energia do ambiente de sedimentação;

- treinar técnica de localização de ponto de observação com mapa e GPS;

- treinar técnica de coleta e identificação de amostra;

Atenção: as amostras deverão ser secadas e trazidas na aula de 27 de junho para análise das texturas.

\section{CADERNETADE CAMPO}

Para cada ponto de observação, seguir o seguinte roteiro e complementar com os questionamentos específicos:

1) identificação do ponto de observação;

2) localização do ponto, de tal forma que qualquer um que ler sua descrição possa retornar e identificar o local!;

3) Descrição do ponto: tipo de afloramento, esquemas da exposição etc.;

4) amostragem: descrição do tipo de amostragem e identificação da amostra coletada (código).

Saída da USP: observar como é o relevo desde a cidade de São Paulo até a Serra do Mar.

É correto chamá-la de serra?

Qual é a finalidade da Usina de Traição no Rio Pinheiros, próximo da Ponte do Morumbi?

\section{Descida da Serra do Mar}

Observe as obras de contenção da encosta. Qual é a finalidade dos canos que saem das paredes?

As moradias que são visualizadas ao longo da Rodovia Anchieta são conhecidas como "Bairros Cotas”. Quais os problemas geológicos aos quais essas moradias estão sujeitas?
Parada 1. Vista Panorâmica da Serra do Mar e Baixada Santista - Rodov. Anchieta km 45

- identifique o ponto e sua localização;

- marque o ponto no mapa topográfico e confirme com os dados do GPS;

- quais tipos de materiais geológicos você imagina que encontrará na Baixada Santista?

- qual seria a origem da Serra do Mar e de do relevo escarpado? Vulcanismo? Erosão de rochas antigas?

- por que o intemperismo na Serra do Mar é tão intenso?

Parada 2. Vista da Serra do Mar

- observe a Serra do Mar e imagine os problemas para transposição durante a descoberta do Brasil;

- observe no mapa topográfico, localize o ponto e o Vale do Rio Cubatão;

- qual seria a feição geológica que teria originado a escavação desse vale?

- até a próxima parada, passe a observar o rio que corre paralelo à estrada e os materiais geológicos.

Parada 3. Sedimentos do Rio Cubatão - abaixo da pista nova da Rodovia Imigrantes

- observe os pilares da Rodovia Imigrantes. Qual seria a função dos anéis de concreto ao redor dos mesmos?

- localize o ponto no mapa topográfico. Existe diferença na topografia desse ponto para a área a jusante?

- no rio observe e descreva os tipos de sedimentos. Ocorre variação no tamanho dos grãos (granulometria)?

- colete e identifique três amostras: dos seixos, da areia e da fração de minerais pesados (mais densos), separados com uso da bateia;

- quais são os minerais mais comuns nas areias? Explique qual seria a origem dos mesmos. Veja com o imã como se comportam os minerais pesados. Qual seria a origem de parte desses minerais?

- existe nesse local alguma evidência geológica que 
explicaria o entalhamento do Rio Cubatão?

- qual seria o uso econômico desses sedimentos? Responda levando em questão os problemas ambientais;

- observe o perfil longitudinal esquemático de um rio e posicione o ponto de observação. Identifique qual seria o nível de base e o que ocorreria se ocorresse sua variação vertical para cima ou para baixo.

Parada 4. Mangue - Rodovia Padre Manoel da Nóbrega, km 279, a oeste do pedágio

- como é a topografia dessa região comparada com o da parada anterior;

- como são os sedimentos? Há diferença de tipos ou existe apenas um tipo?

- o que é e como se origina o material de cor preta?

- haveria alguma finalidade econômica para esse material?

Comente levando em consideração a questão ambiental;

- esse material é permeável ou impermeável?

- observe a ponte sobre o canal. Onde estaria a base (fundação) da ponte? No sedimento?

- existe ocupação humana na área de mangue? Comente;

- colete uma amostra representativa desse sedimento.

Parada 5. Extremo nordeste da Praia Grande - Fortaleza de Itaipu

- observe os grãos de areia da praia. Quais são os minerais presentes? A fração de minerais pesados é a mesma da do Rio Cubatão? Como é a textura dos sedimentos (granulometria, arredondamento e seleção)? Explique;

- qual poderia ser o uso econômico dessas áreas? Comente levando em consideração o meio ambiente e problemas quanto ao uso tecnológico de areias de praia na construção;

- qual seria o objetivo estratégico da construção da fortificação?

- a região de São Vicente e Santos foi uma das primeiras localidades a ser ocupada pelos colonizadores. Por qual motivo não ocorreu grande expansão como no caso do Rio de Janeiro? O motivo teria sido político ou existe algum impedimento natural?

- lembre-se das diferenças do relevo que existe entre o Litoral Sul e o Litoral Norte do Estado de São Paulo e compare as praias das duas regiões. Qual seria o motivo da diferença?

- existem evidências geológicas de sedimentos marinhos em posições altimétricas de alguns metros acima do atual nível do mar com idades entre 5000 a 6000 anos. Devido ao fato desses sedimentos marinhos situarem-se estratigraficamente sobre sedimentos continentais, podemos dizer que há 5.000 anos atrás teria ocorrido regressão marinha ou transgressão marinha?

\section{Sugestão de leitura}

- Sobre a Light e o Sistema Billings http://www.ambiente.sp.gov.br/EA/adm/admarqs/ AntonioAugusto.pdf

- texto "Biografia de um grão de areia" de Paulo César Giannini - Decifrando a Terra pg. 170.

- SANTOS, A. R. dos. A grande barreira da Serra do Mar: da trilha dos Tupiniquis à rodovia dos Imigrantes. São Paulo: O Nome da Rosa, 2004. 122 p.

\section{Instituto de Geociências - USP 2006 044100 - Geologia Geral - Sistema Terra (Bacharelado) Aula de Campo VI: Preparatória para Mapeamento Final - Itu}

Parada 1. Parque Rocha Moutonnée, Salto, SP

$\mathrm{Na}$ área do parque, observa-se contato entre rochas do Subgrupo Itararé (Permo-Carbonífero, entre 359-251 Ma) e Granito de Itu (580Ma = Neoproterozóico), que constitui o embasamento local. Note a grande diferença de idades. Como explicá-la?

Pontos a observar:

- feições superficiais do granito e sua distribuição sobre o embasamento. Note que a rocha foi parcialmente lavrada;

- observe que há outros tipos de rochas, principalmente sedimentares, além do granito, desecreva a relação entre as rochas.

Questões:

- que tipo de contato ocorre entre o granito e as rochas sedimentares?

- quais são as rochas sedimentares presentes?

- a morfologia do granito e suas feições superficiais indicam um tipo de estrutura geológica relacionada à ação de que agente geólogico. Como se chama essa estrutura ?

- que tipo de informação a estrutura nos fornece quanto à paleogeografia da região, durante o P-C ? 
Parada 2. Rodovia Itu-Jundiaí (xenólitos e possível contato granito-gnaisses regionais)

- desenhe um dos afloramentos (ou corte de estrada, ou matacões quebrados), salientando as feições geológicas (homogêneo ou heterogêneo, fraturas, xenólitos etc.). Anotar as observações principais e lembrar de colocar escala;

- descreva a rocha ígnea predominante (estrutura, textura, granulação, mineralogia, cor) e classifique-a;

- o que significa “xenólito”? Qual o mecanismo que gera uma estrutura como a observada?

- mudando a escala de observação, observe agora a paisagem: observa-se algum contraste (topografia, presença ou ausência de matacões, relevo acidentado ou não etc.)? Como explicaria essas diferenças? Esses contrastes ajudam na tarefa do mapeamento? É possível interpretar qual seria o tipo de contato litológico? De que tipo: intrusivo, normal, tectônico? Seria um contato "observado” ,"verificado”, “aproximado”, ou “inferido”?

Parada 3. Rodovia Itu-Jundiaí (mar de matações no interior do Granito Itu)

- observe um ou vários matacões, ou um corte de estrada, e desenhe as feições observadas (forma, tamanho, estrutura interna etc.), com escala. Anote suas observações;

- descreva a rocha conforme os critérios da parada anterior e classifique-a;

- como se gerou o “mar de matacões” observado durante os últimos quilômetros de percurso? Descreva sucintamente o fenômeno geológico inteiro (invasão de magma, formação de corpo ígneo em profundidade, soerguimento e erosão, intemperismo). Pergunta-se agora:

- qual o nome do corpo ígneo?

- é possível estimar a profundidade inicial de resfriamento do magma?

- espera encontrar um “mar” similar de matacões, marcando os afloramentos dos basaltos da Bacia do Paraná? Explique;

- descreva o "solo" que predomina nessa região quanto ao tipo de minerais presente explique. Qual o processo que gera os matacões? Espera encontrar aqui afloramentos de granito na forma de "lages”? Explique.
Parada 4. Rod. Marechal Rondon - Itu-Porto Feliz (lavra no Grupo Tubarão, Subgrupo Itararé), próximo à Fábrica Schicariol - quais litologias observamos neste local?

- esquematize o afloramento, indicando os contatos entre os diferentes tipos de rocha (em escala);

- que tipos de estruturas sedimentares podem ser vistas? Descreva-as, com desenhos.

Parada 5. Parque do Varvito (Itu)

- observe a parede principal da pedreira. Esquematize-a em escala. Responda:

- qual é a estrutura mais notável da rocha local?

- a espessura das camadas varia? De que modo? Qual seria uma possível causa dessa variação?

- que outras estruturas sedimentares você identifica no afloramento? Anote pelo menos duas estruturas;

- qual teria sido a origem dos planos verticais observados na pedreira?

- há evidências de fósseis? De qual tipo?

\section{Bibliografia}

ALMEIDA, F. F. M.; CARNEIRO; C. D. R. Geleiras no Brasil e os parques naturais de Salto e Itu. Ciência Hoje, Rio de Janeiro, v. 19, n. 112, p. 24-31, 1995.

INSTITUTO DE PESQUISAS TECNOLÓGICAS. Mapa Geológico do Estado de São Paulo. São Paulo: IPT, 1981. Mapa. Escala 1:500 000. (Nota Explicativa).

ROCHA-CAMPOS, A. C. Rocha moutonnée de Salto, SP. In: SCHOBBENHAUS et al (Ed.). Sítios geológicos e paleontológicos do Brasil. Brasília: DNPM/CPRM/SIGEP, 2002. p. 155-159. Disponível em: <http://www.unb.br/ig/ sigep/sitio021/sitio021.htm>.

ROCHA-CAMPOS, A. C. Varvito de Itu, SP. In: SCHOBBENHAUS et al (Ed.). Sítios geológicos e paleontológicos do Brasil. Brasília: DNPM/CPRM/SIGEP, 2002. p. 147-154. Disponível em: <http://www.unb.br/ig/sigep/ sitio062/sitio062.htm>. 